\title{
Measuring Enrichment Liability in the Context of Unfinished Construction Projects
}

\author{
Aimite Jorge \\ Commercial Law Department, University of Namibia, Windhoek 9000, Republic of Namibia
}

\begin{abstract}
Most aspects of construction projects mainly fall under contractual regime. However, when things go wrong such as when the project is abandoned for various reasons, they may create two different scenarios: a contract that is breached and a fixed structure that is left on the land which may constitute an incomplete benefit that is acquired by one of the parties. The transfer of such benefit is initially made with a legal ground, but that ground has since ceased to exist. If some aspect of that benefit cannot be recovered under a contract, enrichment rules may be competent to solve the problem. How to measure the different aspects of that enrichment is however a problem that may have different interpretations according to different conceptions of the foundations of enrichment liability in a particular legal system. This article explores the measures of enrichment in such cases of failed bilateral contracts scenarios working from South African perspective. It argues that in cases of failed bilateral contracts generating an enrichment situation, sanctioning a dual measure of enrichment in a legal system may be an appropriate avenue.
\end{abstract}

Key words: Remedies, unjust enrichment, failed bilateral contracts.

\section{Introduction}

When parties enter into a contractual relationship, it is not always the case that the contract will be performed without mishaps. The source of that mishap may be a previously undiscovered situation or a subsequent event. But it is germane to a contractual relationship that it is a risk taking endeavour in the sense that the parties having such an endeavour will have expectations as to the outcome of the contracting process, and some of which may not be fulfilled. When the contractual relationship comes to a halt for any unforeseen reasons, the courts, in the absence of prior agreement to the contrary, will play the role of risk allocator. Cases of unfinished construction projects are illustrative of this risk allocation situation. In these cases, what exactly happens is that a risk of loss has emerged or materialized and it must be decided by the court where that risk lies. Depending on how the agreement comes to a halt, the situation may create an unjust enrichment of one party at the

Corresponding author: Aimite Jorge, Dr., senior lecturer, research fields: construction law, contracts and unjust enrichment. E-mail: ajorge@unam.na. expense of the other. However, although the availability of an enrichment remedy does not depend on a breach of contract. Nevertheless, there is usually an overlap between enrichment and contractual liabilities where the breach of contract does result in an unjust enrichment.

In this paper, the author explored the issue of enrichment liability in failed bilateral contracts in the form of abandoned or unfinished construction projects. The aim is to analyze the extent to which unfinished construction projects transcend the realm of mere contract breach, as they are prone to creating residual enrichment claims. Depending on the particular circumstances of each case, failed bilateral contracts generating an enrichment liability should be scrutinized more carefully when it comes to measuring the extent of the enrichment. The analysis and discussion are mainly worked out from South African perspective but with wider view in mind.

The discussion is structured as follows: first, it makes a brief excursus of ineffectiveness of contracts due to breach and frustration of purpose; second, it describes what an unfinished project is and uses an 
illustrative example of an unfinished motorway among others; third, brief description of various payment/pricing methods and their possible implications; fourth, a brief analysis of the measure of enrichment; and finally the conclusions.

\section{Ineffectiveness of Contracts due to Breach and Frustration for Impossibility}

The situation of an "enrichment claim” arising from breach of contract in so far as the measure of recovery is concerned may be complex and ambivalent. It may depend on whether the claim is for services rendered pursuant to a contract which is subsequently terminated by breach, or whether it concerns other contractual situations. There is also no single encompassing view on the issue for all legal systems. Amongst the practical answers, there is a view that the calculation of the enrichment relief in cases of breached contracts should be made by reference to the market value, because a contractually based limitation is flawed for two reasons: firstly, because such "limitation may not reflect a number of benefits, financial and otherwise, that may flow from the ability to complete performance" [1]; secondly, such measure may deprive the innocent party of "an opportunity to reduce the anticipated losses to be sustained by full performance through a possible range of cost reduction techniques".

Another practical view contends that, in cases of contracts for services, there should be two different approaches in cases of breach. It first should depend on whether the alleged breach is related to what is sometimes described a breach of warranty or a breach of a condition. If the defendant merely breached a warranty, that is to say, the defendant's breach of contract does not substantially deprive the plaintiff of what he expected to receive, then, the solution is that neither party is excused from further performance [2].

In contrast, if it is a breach of a condition, that is to say, the defendant's breach does deprive the plaintiff of what she/he expected to receive (a fundamental breach). Then, the innocent party should generally have a choice as follows: first, he may affirm the contract and insist upon completion of the agreement as initially contemplated. If he does so, he must then fulfil his end of the bargain. However, he is also entitled, under an action in breach of contract, to claim compensatory relief with respect to losses arising from the defendant's act of breach; secondly, as alternative solution, he may terminate the contract and thereby release both parties from the need to perform any primary obligations that remain outstanding. If he exercises this later option, he also may have a choice as follows: he can bring an action in breach of contract and claim compensatory relief with respect to losses arising from the defendant's act of breach. Alternatively, he may be able to bring an enrichment action and claim restitution of any benefits that he conferred upon the defendant [3]. Despite what is mentioned above, normally even if the claimant terminated the contract on the basis of the defendant's breach of a "condition” (fundamental breach), the plaintiff cannot escape the consequences of a bad bargain by means of contractual relief. He is generally entitled to choose between expectation damages and reliance damages. Obviously, each option is compensatory in so far as it aims to repair a loss. The former pertains to benefits that the plaintiff expected to receive under the contract, whereas the latter pertains to losses that the plaintiff incurred as a result of relying upon the agreement. In either event, however, relief will normally be refused to the extent that the claimant entered into a losing contract $[2,4]$.

If termination is not due to breach, but due to frustration of purpose on account of impossibility, then the solutions of common-law systems differ from the civilian-legal systems. One of the main differences between the legal systems on the doctrine of impossibility of performance comes down to the primary remedy for breach each system subscribes, too. On the one hand, if a system provides that its primary remedy is specific performance [5] then, as a 
logical consequence, if performance of the obligation becomes impossible, the obligation is discharged [6]. That is so because the courts cannot enforce an obligation that is impossible-impossibilium nulla obligation est (there is no obligation to do the impossible) [7]. This rule comes from the Roman Justinian Digest 50.17.185 (Book 50, Chapter 17, Paragraph 185) as enunciated by the Roman Jurist Celsus [8]. On the other hand, if a system subscribes to the damages (compensation) approach as the primary remedy for contractual breach, excluding exceptions, then on the occurrence of the impossiblility, the value can always be given, unless it is entirely infeasible.

\section{What Is an Unfinished Construction Project?}

An unfinished construction project normally is a building (or any other architectural structure such as a bridge, a road or a tower) where construction work was either abandoned or put on hold at some stage in the process. In extreme cases, the project may actually exist in a design form only. Some unfinished projects in design forms are in a blueprint or a white print alone. One such example is the California-Santa $\mathrm{Fe}$ Bullet Train Project that was never built, and its costs at the time was estimated at US $\$ 2.1$ billion, but according to many other estimates, it would have escalated to more than US $\$ 5.3$ billion by the time the project would have been completed. This project has now been resurrected again in different form. But the concept of unfinished construction projects in this paper refers to an actual building or structure which either has been started but abandoned during construction or is actually being built, but the process is constantly delayed or the progress of the work is at the speed of a snail. Sometimes a construction or engineering project remains unfinished at various stages of its development. Examples of unfinished works abound around the world and there is no need to single out one example, except to say that some buildings or structures are partially constructed and can be used in their current unfinished state or forms, while others remain mere shells. In some interesting cases, the projects are intentionally left with an unfinished appearance (leaving a building in unfinished state was more the follies of Europe in the 16 th and 17th centuries). But other projects or works are in the process of a near-perpetual construction (an example of these perpetual constructions is Antoni Gaudi's Sagrada Familia Church in Barcelona, Spain, which has been in construction for 120 years and is now projected to finish in the year 2026). Another example in the same category in South African context is the unfinished structure in Cape Town, the freeway called Eastern Boulevard (the completed section of this Cape Town freeway is now called Nelson Mandela Boulevard) in Foreshore. This Cape Town project was conceptualized as part of a ring-road in the 1960s [9] and has yet to be completed. Construction was halted in 1977 allegedly at the time when there was no justification in terms of traffic demand for the completion of the inner viaduct. Close to the 2010 Soccer World Cup in South Africa, residents were asking what response the city would give to visitors of such an unfinished project in a very touristic area, leading to the Cape Town world Cup Stadium. Unofficial justifications varied but all seemed to agree that the motorway would not be finished any time soon due to Cape Town municipality budget constraints [10]. In its current design form, apparently, there are no private companies willing to take up the project to finish it either at a reasonable cost.

For the purpose of this paper, the descriptive example of the unfinished Cape Town Eastern Boulevard freeway will partially serve to illustrate some features of the construction-contract model that might have been used in that process and other related problems. Recent announcement in the news state that the Cape Town freeway structure is finally now at the mercy of University of Cape Town civil engineering 
students to come up with innovative ideas, new designs and proposals to resurrect the project by 2014 [11]. Obviously, when the students' ideas are put into proposals and plans, new tenders will be invited again after an existing plan idling for 30 years. This Cape Town freeway gives us insight into common problems facing unfinished projects. Such problems usually have roots at the inception stage. Nonetheless, the aim of this paper is on enrichment measures on failed bilateral contracts. One will simply look at the model of construction contract used in such projects to understand the implications on the remedies.

One of the questions that arises in such examples is whether ordinary allocation of risks in breach of contract will resolve all the problems or whether the unfinished work might have produced an enrichment situation for one of the parties or both. In essence, the issue is really about risk allocation in these cases. If there is an enrichment claim, it arises out of the failed bilateral agreement. The claim in these cases should always stick to the value received and not necessarily opting for value remaining. Before addressing specifically this question of enrichment claim and the concomitant measure of recover, it is necessary first briefly discuss some prominent payment and pricing methods in construction contracts used today within the industry.

\subsection{Lump Sum Payments and Unfinished Projects}

One potential problem that can create enrichment scenario in unfinished project is a contract for a lump sum and cost-plus payment.

Amongst the functions of construction, contracts are serving as means of pricing construction. At the same time, the contracts also structure the allocation of risk to the various parties involved. Because of this, normally, the owner is in a position to decide the type of contract to be used for his/her project and to set forth the terms in a contractual agreement. For this reason, it is important to understand the risks of the contractors associated with different types of construction contracts. In the process of contracting, the parties may have chosen a specific pricing model for their contract such as a lump sum contract [12], unit price contract, cost plus fixed percentage contract [13], cost plus fixed fee contract [14], cost plus variable percentage contract, target estimate contract or guaranteed maximum cost contract.

A brief explanation of these pricing methods is as flows: (1) in a lamp sum contract, the owner in effect assigns all the risk to the contractor. The contractor, in turn, can be expected to ask for a larger mark-up in order to cater for unforeseen contingencies; (2) the cost-plus-fixed percentage contract is normally used for constructions involving new technologies or in cases of extremely pressing needs such as in the urgency of construction of military installations. In this type of contract, the owner usually assumes all risks of costs overrun because the contractor will receive the actual direct job plus a fixed percentage. In these cases, the contractor has little incentive to reduce job cost; (3) the cost-plus-fixed fee contract: in this type of contract, the contractor receives the actual direct job cost plus a fixed fee. The contractor will have some incentive to complete the job quickly since its fee is fixed regardless of the duration of the project. The downside here is that the owner still assumes the risks of direct job cost overrun while the contractor may risk the erosion of its profits if the project is dragged on beyond the expected time; (4) a GMP (guaranteed maximum price) contract is a variation of cost-plus agreement. Essentially, the GMP is a cost-plus agreement with a cap on the owner's total liability for the cost of construction of the project. The owner is obliged to pay the contractor for the actual cost of the construction up to a certain sum. If the construction cost exceeds that sum, the contractor is liable for the cost overrun; (5) target estimate contract: this is a form of contract which usually specifies a penalty or reward to a contractor, depending on whether the actual cost is greater than or less than the contractor's estimated direct job cost. Usually, the 
percentages of savings or overrun to be shared by the owner and the contractor are predetermined and the project duration is specified in the contract. Bonuses or penalties may be stipulated for different project completion dates.

However, a detailed discussion of each of these pricing methods is beyond the scope of this paper. A single illustration of the architectural services may suffice to highlight the main point for this paper.

Normally, architects (and other specialty services) are often remunerated a certain percentage of the overall cost of the project (as an example, the current fees tariff in South Africa were published on December 2nd, 2011 for the year 2012). Sometimes other pricing criteria are used just as mentioned above.

The question that arises in such circumstances is that: to what extent, such percentage of the project is fully payable to the architect/engineer at the time of abandonment of the project, if their work and role in the project would involve not only supplying the drawings for the contractor, but also ensuring that those drawings are implemented as specified in the contract documents such as a continuous observation role of the contractor's work at different stages? Is the full percentage due if the project is unfinished?

To illustrate this point, we should consider the following: in many construction projects, earthwork covers foundations and underground plumbing, while a gypsum board covers ceilings and wall framing. In a normally progressing construction project, the timing of such observations would be different. The task of earthwork and underground plumbing would be at the initial stage of the construction, while the task of observing the gypsum board and wall framing would be at a later stage [11]. That is so because if the architects were to observe the work after the components are hidden, it would defeat the purpose of observation. Despite these tasks being at different stages of the project, an architect may have billed the owner a lump sum for the whole work. When the project is left unfinished, the problem may arise as to what sum is the owner liable in the process. If the owner is liable for the full percentage amount of the original overall cost of the project, part of that sum would be paid to the architect when it was not due. Conversely, if the contract provided that the architect would only be paid for the observation task at the end of the project, the owner would be left with a standing structure that may constitute an actual enrichment, a benefit acquired. In the first example, there is a possibility of partial payment, or if deposits were already made, a set-off could be used for the part performance. But that does not solve the whole problem.

\subsection{Unfinished Projects Transferred to New Investors}

When unfinished buildings can partially be used in their unfinished state or where the project was initially publicly funded and the right to the structure is directly transferred to investors either to finish the project, or to completely alter it, several problems may develop. Some projects, such as apartment buildings, may have had certain buyers pay in advance of construction for their future apartments in order to secure the best spots in the building. When that project is abandoned or progresses extremely slowly and, at some stage, the right to the building is directly transferred to an investor, original buyers who might still be willing to keep the same apartments may find themselves paying significantly extra amounts for essentially the same product they bought earlier. In these situations, a double sword problem arises. If the new investors are willing to finish an unfinished building project opting to stick with the previous buyers at the same price they bought the apartments at the project's inception stage, the investors stand to lose because the market price might have shifted significantly at that stage. If the buyers relinquish their right to the previously bought property in an unfinished building, the investor may gain an undue benefit for keeping the structure that is more valuable than they will refund to the buyers. What are the 
remedies in these circumstances?

Can the buyers simply be satisfied for a claim for damages when the building project goes unfinished? Do damages solve the whole problem in these circumstances or are there residual remedies available to the buyers?

And when buyers had paid in advance but the currency significantly fluctuated between the time the building was abandoned and the time the rights to the building are transferred to a new investor, and the currency is now weaker, there arises the possibility of an unjustified enrichment of one of the parties.

\subsection{What Can Be Gleaned from the Situation of Unfinished Construction Projects?}

In effect, the situation of unfinished construction projects is, to an extent, a reflection of a losing contract. There is no unanimity about what exactly a losing contract entails. The expression "losing contract" itself is ambiguous. There is, however, some convergence: all legal systems abhor applying enrichment liability to contractual relationships. Such an aversion of the legal discourse in applying enrichment rules to contractual settings usually protects the contract itself. The rationale of not applying enrichment liability is to prevent opening unnecessary loopholes where one of the parties might be tempted to terminate a losing contract thereby subverting the regime of risk allocation voluntarily undertaken under the agreement. The difference, however, with unfinished projects, is that the contract has in effect come to an end. What is really at issue is winding up the consequences of such a failed bilateral contract. The fact that the work has been left unfinished obviously shows that prima facie the contract was breached, because there is no reasonable person who would enter into a contract to leave the project unfinished.

Be that as it may, in principle, all contract breaches occur because the contract is a loser for one side, although not all such contracts are considered "losing contracts". Illustratively, using an economic concept of profitability, sometimes, it is observed that not all "losing contracts" are jointly unprofitable, and not all jointly unprofitable contracts are "losing contracts" [15]. A "losing contract" is one in which the breaching party is not the "loser" but the party who appears to be advantaged by the contract, that is to say, the wrong person (apparently) breaches. The problem can occur in contracts that are jointly profitable and contracts that are jointly unprofitable. However, the restoration remedy is normally appropriate in both cases. In losing contract cases, the court does not need to decide whether the contract is jointly profitable. The joint profitability determination matters when the court must choose between expectation and reliance.

The interrelation of contractual and enrichment actions in the losing contract scenarios is however a difficult issue. Basically, the theoretical difficulty encountered in determining whether or not an enrichment claim which ought to be available in the case of a losing contract lies in the fact that the question can be approached from different perspectives. It "may be viewed in terms of contractual principles only or from the point of view of unjust enrichment or a combination of both" [16]. If the problem is approached exclusively in terms of contractual terms, then unfinished projects should simply be seen as mere cases of rescission or cancelation of a contract. In this case, the reliefs available under these forms of breach should suffice to satisfy the aggrieved party.

On the other hand, "a defaulter's contention that the aggrieved party's negative expectancy is taken into account certainly will lack appeal when he has been given nothing, except a broken promise, in exchange for the performance received" [12]. Therefore, in such cases, considerations of unjust enrichment become applicable. Since justice does not require the party in default be permitted to retain an amount (or value-benefit) for which he gave nothing, merely by reason of the fact that the aggrieved party would have 
lost that amount he (the defaulter) had performed the contract which in fact he did not perform. In essence, if the issue is viewed solely in terms of unjust enrichment, the focus is laid instead on the assets unjustly held by the party in default. Because considerations of enrichment do not emphasise the aggrieved party's benefits and losses under the contract, he is, therefore, entitled to restitution, in kind or in value, of the performance rendered unless justice requires otherwise $[12,17]$.

In essence, the discussion of unfinished projects is really about risk allocation. In pursuing the task of risk allocation in such cases, the obvious starting point will always be to consider the parties' own intention in relation to the risk at the inception of the agreement. Such intention may be ascertained by reference to the terms of the contract. Normally, it will be assumed that a rational individual entering into reciprocal exchanges will have made arrangements for events which create a risk of loss [13]. Some parties are naturally averse risk, others are neutral risk, and yet, others are naturally risk takers. Accordingly, those who are averse risk may have made arrangements through the use of different mechanisms to ward off any supervening risk. Ordinary mechanisms are the use of "force-majeure" clauses, exemption clauses, the designation of a term as condition or a warranty or a cancellation clause [14]. These and the like devices serve to allocate the risk of loss according to the terms of the contract. If the other party was prepared to accept the risk, a normal risk taker, the reason may be that he believed to have been in a better position to cover the risk either by insurance or otherwise. If such party is less risk averse than the other party and is prepared to take the consequences if the risk did arise, then he should suffer the consequences. But that is not necessarily clear in the cases of unfinished construction contracts. In these cases, it is also necessary to take into account the type of contract used and other ancillary issues.

For example, the parties may have made provisions for the use of a CMAA (construction manager as agent) contract style. The CMAA model is mostly used in complex projects [18]. This construction-contract method makes a general contractor redundant as it envisages an independent $\mathrm{CM}$ (construction manager). In this CMAA contractual model, the owner retains a $\mathrm{CM}$ as the owner's agent to advise on several issues, including costs, scheduling, site supervision, site safety, construction finance administration and the overall building construction. It must also be observed that the CM is not a contractor, but simply a manager who plays no entrepreneurial role in the project (unlike the general contractor, who assumes financial risks in the project).

In the CMAA construction-contract model, the owner usually awards multiple contracts to various trade and specialized contractors, whose work is coordinated by the $\mathrm{CM}[18,19]$. Hence, using this model, for example, the structural framework of the building may be erected by one contractor, masonry work done by another, interior drywall work by yet another and so on. In this model, each contractor is referred to as the prime-contractor who may have one or more subcontractors.

Thus, the owner, by assuming part of the role of the general contractor, eliminates the general contractor's mark-up on the work of the subcontractors. The owner may also receive a reduction in the fee charged by the architect for contract administration. Although these savings are partially offset by the fees that the owner pays to the $\mathrm{CM}$, there can still be substantial savings in large but technically simple projects [20].

The CMAA construction contract model is particularly attractive to owners who are knowledgeable about the construction process and can participate fully in all of its aspects, from bidding and bid evaluation to the closeout phase. However, this advantage comes at a price. In the CMAA construction, contract model essentially occurs that the owner assumes liability risk. On the other hand, in 
the design-bid-build model, such liability risk is assumed by the general contractor [21, 22]. Again, because of the multiple prime-contractors and subcontractors, the CMAA model does not localize the ultimate responsibility at single point among the various prime contractors. In this model, each prime contractor has a direct contract with the owner. Because of such direct contract with the owner, the CM does not have much leverage to ensure timely performance. Therefore, the likelihood of a project being left unfinished also increases.

From the example above, it becomes evident that it is important to construe the language of the contract when it fails. When the project is left unfinished, it is important to ask whether the problem is one of "impossibility" or frustration or mistake at the inception stage. For example, if the parties did make provisions for an event which would not otherwise be regarded as frustrating event, the court may ask whether the relevant provision is worded so as to cover the event of an unfinished project.

\section{Conclusions}

The discussion above highlighted that an enrichment claim can arise from failed bilateral contracts. However, where an enrichment claim arises from those scenarios, one must be careful whether mutual exchanges have occurred. In the cases of unfinished construction projects, the issue comes down to how the parties allocated the risk at the inception stage of the contract. If there was no clear allocation of the risk, an important consideration in the risk allocation process will be to establish what party is the least cost avoider. In this regard, a relevant factor is that one of the parties to a contract may have been in a better position than the other to prevent the risk of loss from materializing, in which case, rules of risk allocation may suggest that this is the person who should accept the risk of loss.

In the same vein, it is said that a person who brings about a frustrating event through his own actions cannot rely on the rules of frustration of contract, on the basis that the law does not give relief in respect of self-inflicted frustration. Similarly, a person who could have performed his contractual obligation in some other perfectly reasonable manner may be required to accept the risk of loss and will not be able to treat the contract as frustrated when the manner of performance which he had contemplated is no longer possible. This principle is sometimes reflected in the rule that an external event must frustrate the common intention of both parties to the contract. To put it differently, in cases of failed bilateral contracts generating an enrichment claim, the measure of enrichment is normally what was received and not necessarily what survives or remains in defendants' hands at litis constatio (contestation of the suit). Loss of enrichment or change of position in these cases is normally not applicable.

\section{References}

[1] P. Maddaugh, J. McCamus, The Law of Restitution, 1st ed., Canada Law Book, Toronto, 1990.

[2] M. McInnes, The measure of restitution, University of Toronto Law Journal 52 (2002) 163-215.

[3] S. Waddams, The Law of Contract, 6th ed., Canada Law Book, Toronto, 2010.

[4] M. Bryan (Ed.), Private Law in Theory and Practice, Routledge-Cavendish, New York, 2007.

[5] A. Schwartz, The case of specific performance, Yale Law Journal 89 (1979) 271-307.

[6] S. van der Merwe, L.F. Huyssteen, M.F. Reinecke, G. F. Lubbe, Contract: General Principles, 3rd ed., Juta Publising, Cape Town, 2007.

[7] R. Zimmermann, Law of Obligations: Roman Foundations of the Civil Tradition, Juta Publishing, Cape Town, 1990.

[8] T. Mommsen, Digesta Iustiniani: Corpus Iuris Civilis (The Digest of Justinian: Corpus of Civil Law), Vol. I, 13th ed., Paul Kruger Publisher, Berlin, 1920. (in Latin)

[9] S.S. Morris, Metropolis of Tomorrow, Report of the City of Cape Town, City Engineer Department, Cape Town, 1951.

[10] L. Kane, Building the foreshore boulevard: The politics of freeway "artefact", in: Proceedings of the 30th Southern African Transport Conference 2011, pp. 131-137 [Online], http://repository.up.ac.za/bitstream/ handle/2263/17328/Kane_Building\%20\%282011\%29.pdf 
?sequence $=1$ (accessed Nov. 3, 2014).

[11] City of Cape Town News: Cape Town Freeways and Future [Online], http://futurecapetown.com/tag/capetown-freeways/\#.ULh-jKyTyNA (accessed Nov. 3, 2014).

[12] G.E. Palmer, The Law of Restitution, Little Brown \& Co, Boston and Toronto, 1978.

[13] D.P. Visser, Unjustified Enrichment, Juta Publishing, Cape Town, 2008.

[14] D. Oughton, M. Davis, Sourcebook on Contract Law, 2nd ed., Routledge Cavendish, Abingdon, 2000.

[15] G.M. Cohen, The fault lines in contract damages, Virginia Law Review 80 (6) (1994) 1225-1310.

[16] J.R. Harker, The nature and scope of rescission as remedy for breach of contract in American and South African law, Acta Juridica 61 (1980) 62-105.
[17] J.E. Du Plessis, The South African Law of Unjust Enrichment, Juta Publishing, Cape Town, 2012.

[18] D.P.M. Metha, W. Scarborough, D. Armpriest, Building Construction Principles, Materials and Systems, 1st ed., Prentice Hall, New Jersey, 2010.

[19] A. Pressman, Integrated Practice in Perspective: A New Model for the Architectural Profession [Online], 2012, http://archrecord.construction.com/practice/projDelivery/ 0705proj-1.asp (accessed Nov. 3, 2014).

[20] D. Meyers, Construction Economics: A New Approach, 3rd ed., Routledge, Abingdon, 2013.

[21] M. Mehta, W. Scarborough, D. Armpriest, Building Construction Principles, Materials and Systems, 2nd ed., Prentice Hall, New Jersey, 2013.

[22] D. Meyers, Construction Economics, 1st ed., Routledge, Abingdon, 2004. 